\title{
Application of powder filter materials in run-in of engines
}

\author{
Aliaksandar Ilyushchanka ${ }^{1,2}$, Vyacheslav Kaptsevich ${ }^{3}$, Valeria Korneeva ${ }^{3}$, Ruslan Kusin², Igar Zakreuski ${ }^{3}$, \\ Iryna Charniak ${ }^{2 *}$, and Alexey Kusin ${ }^{2}$ \\ ${ }^{I}$ State Research and Production Powder Metallurgy Association, 220005 Minsk, Platonov str.41, Republic of Belarus \\ ${ }^{2}$ State Scientific Institution “O.V. Roman Powder Metallurgy Institute”, 220005 Minsk, Platonov str.41, Republic of Belarus \\ ${ }^{3}$ Belarusian State Agrarian Technical University, Minsk, Republic of Belarus
}

\begin{abstract}
The article discusses the use of powder filter materials (PFM) for cleaning engine oil when running-in internal combustion engines (ICE) of agricultural vehicles at motor repair enterprises. The results of comparative tests of powder, paper and net filter elements (FE) are presented. The design of the equipment for cleaning engine oil during and after run-in the engine is proposed.
\end{abstract}

\section{Introduction}

It is common knowledge that the internal combustion engine is one of the most complex and expensive units of tractors, combines and other agricultural vehicles. It develops its motor potential in the process of operation, therefore it is subjected to a major repair at the enginerepair enterprises in order to extend the service life. This saves energy resources and money. During such repair, replacement or restoration of worn parts and engine runin are performed. Run-in of the internal combustion engine is the final operation, which largely determines its further post-repair resource. In the process of run-in the engine wear rate is higher than under normal conditions of its operation.

Full engine run-in occurs during the technological (bench) and initial operational run-in period [1]. After running in, the used motor oil is disposed or used for other needs. It should be noted that the used motor oil still has a sufficient reserve of operational properties, but at the same time the content of mechanical impurities in it is 1.5-2 times higher than the limit value [1]. Obviously, after removing mechanical impurities with dimensions that pose a threat to engine operation, cleaned engine oil can be reused during the run-in process.

The aim of the work is to substantiate the possibility of using PFM based on tin-phosphorous bronze powders and to propose the equipment design for cleaning engine oil during and after engine run-in.

\section{Experimental results and discussion}

Nowadays paper, glass, ceramic, fabric, felt, and polymer filter materials are widely used. Powder filter materials made of metal powders take a special place among them due to a number of advantages. The main advantage of PFM in comparison with other materials is the possibility of multiple regeneration. This compensates for their higher cost. A large amount of work was performed when testing the performance of bronze filter elements of a disc-shaped form in comparison with serial net and paper filter elements used to clean the oil in the hydraulic system of UMZ-6 tractors [2]. Powder filter elements had a fineness of cleaning $25-30,40,50$, and $70 \mu \mathrm{m}$ and consisted of a set of rings (40 pieces) $2.5 \mathrm{~mm}$ thick with a disc-shaped form with an outer diameter of $61 \mathrm{~mm}$, a hole diameter of $24 \mathrm{~mm}$ and a height of $5 \mathrm{~mm}$. Paper filter elements (2 pieces) of the Regotmas type (with a double corrugated filtering surface) 601T-1-06 TU 112-04-86 had a fineness of cleaning 25-30 and $40 \mu \mathrm{m}$. Net filter elements 60-080 GOST 12242-78 (consisted of 18 rings of disc-shaped form) had a fineness of cleaning $80 \mu \mathrm{m}$. Comparative tests showed the following. All types of filter elements have satisfactory performance in the hydraulic system of UMZ-6 tractors with different fineness of cleaning. Paper filter elements have the highest dirt-holding capacity. Table 1 shows the results of the intensity of clogging of various types of filter elements (dirt-holding capacity) before the activation of the safety valve $(0.28 \mathrm{MPa})$ depending on the amount of contaminant introduced into the hydraulic system. Contamination was carried out by injection of quartz sand portions weighing 20 and 40 g every $3 \mathrm{~min}$. in the cover hole of the hydraulic tank, thoroughly mixed with oil M10-B2 in accordance with GOST 8581-78.

The analysis of the data in Table 1 shows that the amount of quartz sand required for contamination is $440 \mathrm{~g}$ for paper filter elements with a fineness of cleaning $40 \mu \mathrm{m}$, and $440 \mathrm{~g}$ with a fineness of cleaning 25-30 $\mu \mathrm{m}$; for net filter elements with a fineness of cleaning $80 \mu \mathrm{m}-160 \mathrm{~g}$ and for powder filter elements with a fineness of cleaning $25-30,40,50$, and $70 \mu \mathrm{m}$, respectively $280,180,240$, and $200 \mathrm{~g}$. That is, paper

*orresponding author: irinacharniak@tut.by 
filter elements have 2-3 times more dirt-holding capacity compared to powder and net filter elements. This is explained by a more developed (due to corrugation) filtration surface. Whereas, powder filter elements have 1.1-1.75 times more dirt-holding capacity compared with net ones due to the installation of a larger number ( 2 times) of the first ones in the filter body. However, despite the fact that paper filter elements have the highest dirt-holding capacity, they are single-use products, while net and powder filter elements can be regenerated. Table 2 shows data on the performance restoration of the of various types of filter elements after their one-time contamination prior to the activation of the safety valve. The performance restoration of filter elements was carried out by cleaning them from dirt using a nylon brush in diesel fuel, followed by (if necessary) reverse air blowing.

Table 1. The dependence of the pressure drop on the filter element on the amount of contaminant.

\begin{tabular}{|c|c|c|c|c|c|c|c|}
\hline \multirow{3}{*}{$\begin{array}{c}\text { Amount } \\
\text { of } \\
\text { contamin } \\
\text { ant in oil, } \\
\mathrm{g}\end{array}$} & \multicolumn{7}{|c|}{ Pressure drop on the filter element, MPa } \\
\hline & \multirow{2}{*}{$\begin{array}{c}\text { Net } \\
\text { element } \\
\text { fineness } \\
\text { of } \\
\text { cleaning, } \\
\mu \mathrm{m} \\
80\end{array}$} & \multicolumn{4}{|c|}{$\begin{array}{c}\text { Powder element } \\
\text { fineness of cleaning, } \mu \mathrm{m}\end{array}$} & \multicolumn{2}{|c|}{$\begin{array}{c}\text { Paper } \\
\text { element } \\
\text { fineness of } \\
\text { cleaning, } \mu \mathrm{m}\end{array}$} \\
\hline & & & & & & & \\
\hline 0 & 0.02 & 0.060 & 0.060 & 0.080 & 0.12 & 0.10 & 0.060 \\
\hline 20 & & & 0.063 & 0.080 & & & \\
\hline 20 & 0.022 & 0.070 & 0.072 & 0.090 & 0.13 & 0.105 & 0.060 \\
\hline 20 & & & 0.080 & 010 & & & \\
\hline 20 & 0.024 & 0.085 & 0.085 & 012 & 0.14 & 0.11 & 0.065 \\
\hline 20 & & & 0.085 & 014 & & & \\
\hline 20 & 0.030 & 0.11 & 0.105 & 017 & 0.155 & 0.11 & 0.070 \\
\hline 20 & & & 0.12 & 019 & & & \\
\hline 20 & 0.28 & 0.16 & 0.14 & 023 & 0.175 & 0.115 & 0.072 \\
\hline 20 & & & 0.16 & 028 & & & \\
\hline 20 & & 0.28 & 0.19 & & 0.20 & 0.115 & 0.075 \\
\hline 20 & & & 0.25 & & & & \\
\hline 20 & & & 0.28 & & 0.23 & 0.117 & 0.080 \\
\hline 40 & & & & & 0.28 & 0.15 & 0.085 \\
\hline 40 & & & & & & \begin{tabular}{|l|l|}
0.175 \\
\end{tabular} & 0.087 \\
\hline 40 & & & & & & 0.21 & 0.10 \\
\hline 40 & & & & & & 0.24 & 0.115 \\
\hline 40 & & & & & & 0.28 & 0.13 \\
\hline 40 & & & & & & & 0.155 \\
\hline 40 & & & & & & & 0.185 \\
\hline 40 & & & & & & & 0.25 \\
\hline 40 & & & & & & & 0.28 \\
\hline
\end{tabular}

As can be seen from Table 2, both net and powder filter elements almost completely restore their full performance after their one-time contamination with quartz powder. Moreover, the higher the fineness of their cleaning, the more necessary is the reverse air blowing. The test results confirmed that although it is impractical to use filters with PFM filter elements in the field environment due to the inconvenience associated with their removal for regeneration. In stationary conditions, their use is promising for cleaning engine oil during engine run-in.
Table 2. Values of pressure drop on clean, contaminated and regenerated filter elements.

\begin{tabular}{|c|c|c|c|c|c|}
\hline \multirow{2}{*}{$\begin{array}{c}\text { State of } \\
\text { filter } \\
\text { element }\end{array}$} & \multicolumn{4}{|c|}{ Pressure drop on filter element, MPa } \\
\cline { 2 - 6 } & 70 & 50 & 40 & \multicolumn{3}{|c|}{$\begin{array}{c}\text { Powder element, fineness of } \\
\text { cleaning, } \mu \mathrm{m}\end{array}$} & $\begin{array}{c}\text { Net } \\
\text { element, } \\
\text { fineness } \\
\text { of } \\
\text { cleaning } \\
80, \mu \mathrm{m}\end{array}$ \\
\cline { 2 - 6 } & & & & & \\
\hline $\begin{array}{c}\text { Clean oil } \\
\text { and filter } \\
\text { element }\end{array}$ & 0.06 & 0.06 & 0.08 & 0.12 & 0.02 \\
\hline $\begin{array}{c}\text { After } \\
\text { contami- } \\
\text { nation }\end{array}$ & 0.28 & 0.28 & 0.28 & 0.28 & 0.28 \\
\hline $\begin{array}{c}\text { After } \\
\text { washing in } \\
\text { diesel fuel }\end{array}$ & 0.06 & 0.08 & 0.08 & 0.12 & 0.02 \\
\hline $\begin{array}{c}\text { After } \\
\text { washing in } \\
\text { diesel fuel } \\
\text { and air } \\
\text { blowing }\end{array}$ & & & & & \\
\hline
\end{tabular}

The study of motor oil during the run-in process made it possible to find out the size of mechanical contaminants and their accumulation in time (Figure 1, Table 3). Figure 1 shows the dependence of the concentration of contaminants in the engine oil on the time of engine operation, during which the full running-in occurs. As can be seen from Figure 1, an increase in the contamination concentration occurs most intensively during the period of the technological run-in. This is due to the fact that during the technological run-in, the largest amount of wear products, as well as operational, repair, and technological contaminants come to the engine oil. At this stage, contaminants from the air also get into the oil and products of incomplete combustion of fuel are generated.

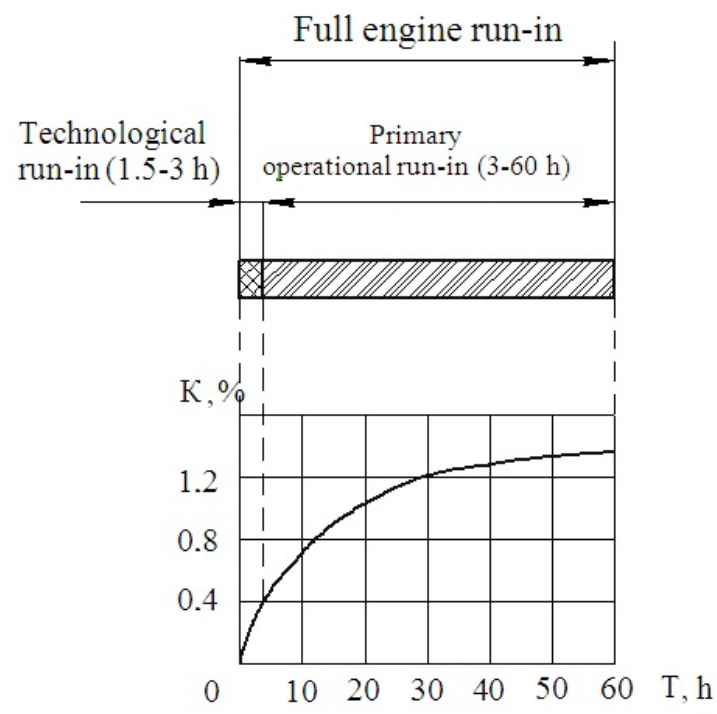

Fig. 1. The dependence of the concentration of contaminants in the engine oil on the time of engine run-in. 
Table 3. Size distribution of contaminant particles during engine run-in.

\begin{tabular}{|c|c|}
\hline $\begin{array}{c}\text { Contaminant particle } \\
\text { size, } \boldsymbol{\mu} \mathbf{m}\end{array}$ & Particle content, \% \\
\hline $8-12$ & 16 \\
\hline $12-16$ & 20 \\
\hline $16-20$ & 18 \\
\hline $20-24$ & 14 \\
\hline $24-28$ & 9 \\
\hline $18-32$ & 7 \\
\hline $32-36$ & 5 \\
\hline $36-40$ & 2 \\
\hline $40-48$ & 4 \\
\hline $48-56$ & 1.5 \\
\hline $56-64$ & 2 \\
\hline $64-72$ & 1.5 \\
\hline
\end{tabular}

The analysis of the data presented in Table 3 shows that the characteristics of PFM based on tin-phosphor bronze powders ensure the removal of the smallest particles from the specified range [3]. At the same time, the use of double-layer structures (Figure 2) provides increased permeability of filter elements and facilitates the process of regeneration.

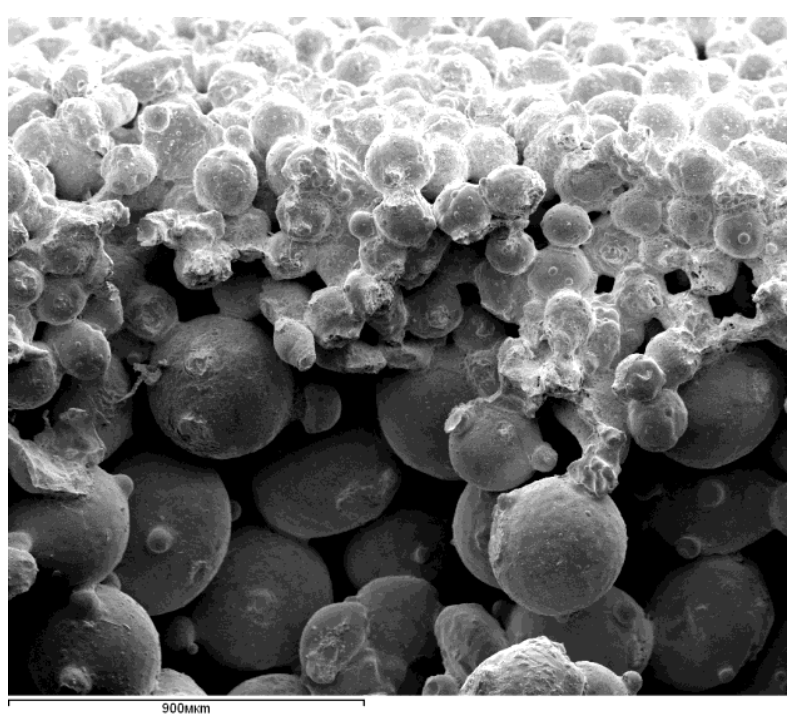

Fig. 2. The dependence of the concentration of contaminants in the engine oil on the time of engine run-in.

According to the conducted research, it was proposed to use the equipment for cleaning the engine oil (Figure 3) with miltiply regenerated filter elements.

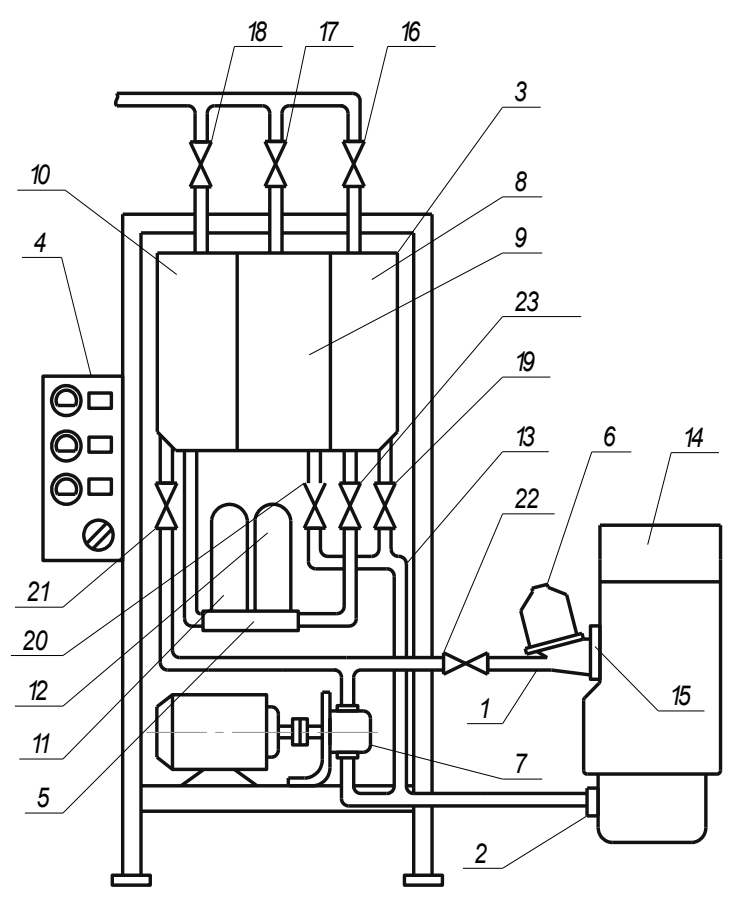

Fig. 3. Equipment for oil cleaning [9]: 1 - Inlet pipe, 2 - outlet pipe, 3 - tank, 4 - control panel, 5 - cleaning unit, 6 - centrifuge, 7 - hydraulic pump, 8 - final cleaning tank, 9 reserve tank, 10 - pre-cleaning tank, 11 - coarse filter, 12 fine filter, 13 - connecting pipe, 14 - engine, 15 - distribution plate, $16-20$ - valves.

The equipment works in the following way. Preliminary cleaned oil, which was previously used during the run-in, comes from the tank 8 and fills the engine oil crankcase; clean oil is filled from the tank 9 to the required level. Pump 7 produced pre-start pumping of oil with closed 21 and open 22 valves. Engine run-in was performed according to a predetermined program with the valve 22 closed. After the run-in was completed, the hydraulic pump 7 was turned on, which delivered used oil being in the crankcase through the nozzle to the centrifuge 6 fixed to the engine 14 . The oil was poured into the crankcase bypassing the engine through the distribution plate 15 sump, and then again repeatedly passed through the centrifuge. Next, closing the valve 22 and opening the valve 21 , the oil cleaned by the centrifuge using the hydraulic pump 7 was supplied from the engine crankcase to the tank 10. Applying excess air pressure, the oil from the tank 10 flowed to the coarse filter 11 and fine filter 12, from where it goes to the tank 8 for subsequent reuse.

The design of this equipment makes it possible to use oil during the engine run-in without residue; not to reduce the quality of reused engine oil, constantly adding fresh commercial oil to it; to eliminate completely the power consumption required for heating the oil; and to refuse from the need to store and recycle the used oil.

Tests at the Berezovsky engine-repair plant showed that oil losses during the run-in of one engine can be reduced by more than 2 times (from 4.9 to $2.3 \mathrm{~kg}$ ). 
Figure 4 shows one of the options for the mobile version of the equipment, providing for the location of three tanks and hydraulic pump outside the device.

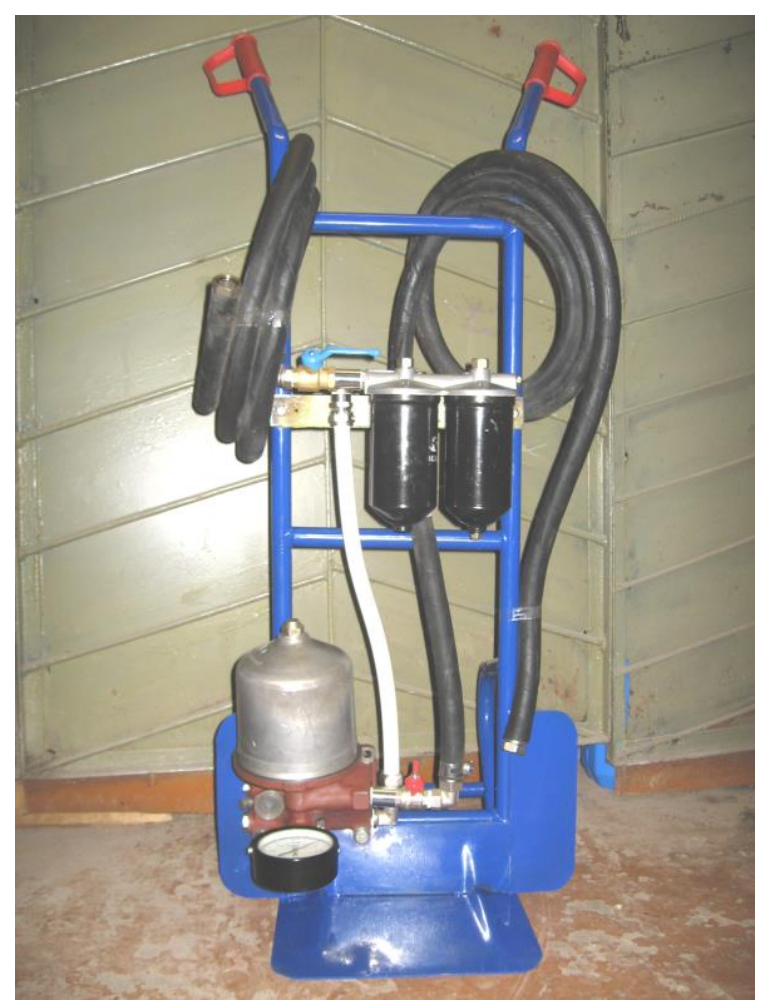

Fig. 4. Mobile equipment for cleaning engine oil.

This equipment can also be used for the preventive cleaning of fresh oils, in which the amount of contamination is above the allowable limits. It can also be used at the enterprises for repair and technical maintenance of the machine-tractor park, as well as directly at the farms.

\section{Summary}

The article discusses the use of powder filter materials for cleaning engine oil during run-in of the internal combustion engines of agricultural vehicles at engine repair plants. The results of comparative tests of powder, paper and net filter elements are given. It has been found that PFM from tin-phosphor bronze powders is a promising material for cleaning engine oil during the engine run-in. The design of the equipment for cleaning the engine oil in the process and after the engine run-in has been proposed, providing oil savings of more than 2 times during the engine run-in.

\section{References}

1. N. Khramtsov, A. Korolev, V. Malaev, Run-in and test of automotive and tractor engines, Moscow: Agropromizdat (1991)

2. V. Kaptsevich, R. Kusin, I. Lykov, G. Bokan, Cleaning of technical oils using powder filter materials // Actual problems of mechanization of agricultural production: Coll. of scientific papers of Int. Scientific and Practical Conf., Gorki: BSAA, 2001. Part 2. P. 103-108

3. P. Vityaz, V. Kaptsevich, V. Sheleg, Porous powder materials and products thereof, Minsk: Higher School (1987) 